\title{
Zur operativen Behandlung der puerperalen Peritonitis und Thrombophlebitis.
}

Von

\section{G. Leopold.}

In einer Arbeit: Zur operativen Behandlung der puerperalen Peritonitis und Pyämie (dieses Archiv. Bd. 78. H. 1) hatte ich über 11 Fälle berichtet, von denen 3 , weil viel zu spät operirt, gestorben waren. Hierzu kam später ein im Zentralblatt für Gynäkologie (1906, No. 43) mitgetheilter Fall von acut aufgetretener Gonokokkenperitonitis im Wochenbett, welcher nach frühzeitiger Laparotomie mit nachfolgender Drainage zur Genesung gelangte.

Sonach beruhten meine bisherigen Erfahrungen über die operative Behandlung der acuten Peritonitis und der Metrophlebitis im Wochenbette auf 12 eigenen Beobachtungen, von denen 3 Frauen nicht hatten gerettet werden können. Bei der Erörterung dieser Fälle und bei der schonungslosen Kritik des eigenen Handelns, die ich in jener Arbeit als unbedingt notbwendig bezeichnet hatte, konnte es für mich keinem Zweifel unterliegen, dass in den 3 nicht geretteten Fällen der operative Eingriff viel zu spät vorgenommen worden war.

Daher galt es von num an, die Beobachtungen am Krankenbett betreffs der Symptome so zu verschärfen, dass der Beginn der acuten Peritonitis mit möglichster Sicherheit zeitlich festgestellt werden konnte, um darnach baldigst die Eröffnung der Bauchhöhle und die Ablassung des Eiters vorzunehmen. Denn die bisher zur Heilung gelangten neun Fälle, welche sämmtlich ernstester Natur waren, hatten bei der Operation mit Sicherheit darüber Aufschluss gewährt, dass solche Massen von Eiter und von Eitererregern (Streptokokken bezw. Gonokokken), wie sie sich hier in der Bauchhöhle vorfanden, durch kein Mittel schneller und besser aus dem Orga- 
nismus zu entfernen waren, als durch eine Operation. Und Jeder, der in der Klinik die betreffenden Fälle vor der Operation in ihrer ausserordentlichen Schwere gesehen hatte, musste bei der Operation zu der vollen Ueberzeugung kommen; 1. dass sich schon in sehr kurzer Zeit nach Beginn des Fiebers bedeutende Mengen von Eiter in der Bauchhöhle ansammeln können, 2. dass die gonorrhoische Infection, welche von Vielen als harmlos für Geburt und Wochenbett angesehen wird, doch mitunter eine so schwere Erkrankung ist, dass sie in kurzer Zeit zum Tode führen kann, dass 3. nach frühzeitiger Operation das Allgemeinbefinden der Kranken sich in der Regel auffallend schnell bessert und endlich dass 4. der operative Eingriff selbst bei weitem nicht so schwer und lange nicht so an- und eingreifend für die Wöchnerin ist, als die acute Erkrankung, an der die. Frau wohl meistens hoffnungslos darniederliegt.

Seit jenen beiden Veröffentlichungen sind nun 6 neue Fälle hinzugekommen, fünf von acuter puerperaler Bauchfellentzündung, und ein Fall von schwerer puerperaler Pyämie (Metrophlebitis), welche sämmtlich der operativen Behandlung unterzogen wurden.

$\checkmark$ on diesen 6 neuen Fällen konnten leider zwei Kranke nicht gerettet werden. Doch wollen auch diese Fälle nicht gezählt, sondern abgewogen sein.

Denn die eine war eine luetische Puella publica im 5. Monat der Schwangerschaft stehend, die noch am Abend vor dem in der Nacht beginnenden Abort mit 6 Männern geschlechtlich verkehrt hatte und schon hochfiebernd und schwer inficirt zur Geburt kam. Bei ihr trat die Peritonitis nicht so acut wie bei anderen Kranken in die Erscheinung. Obwohl die Laparotomie schon am 6. Tag des Wochenbettes erfolgte, kam sie, der schweren Allgemeininfection gegenüber, doch zu spät. Auch die zweite Kranke, welche nicht zu retten war, obwohl die Laparotomie schon am 2. Tage nach Auftreten der Peritonitis erfolgte, erlag einer schon zu weit vorgeschrittenen Sepsis, die nur auf eine schon ausserhalb der Klinik erfolgte künstliche Verletzung der hinteren Collumwand zurückzuführen war.

Es mögen nun zunächst die neuen 6 Beobachtungen folgen, worann sich eine gemeinsame Betrachtung der von nun an zu beachtenden Grundsätze schliessen soll. Aus den Krankengeschichten soll immer nur das Wesentlichste zur Sache Gehörige angeführt sein. 
I.

Peritonitis universalis. Laparotomie am 2. Tage der schweren Erkrankung. Genesung.

Am 19. 11. 06 trat die ledige Tucht., 22 Jahre alt, in die Klinik ein. Musculatur und Knochenbau normal; Herz und Lungen gesund. Kein Eiweiss. Letzte Regel Ende Februar 1906, von mittlerer Stärke. Kolpitis granulosa.

Becken: $231 / 2,26,31 \frac{1}{2}, 17$. Vorberg nicht erreichbar.

Geburt am 23. 12. 06. Dauer 12 Stunden. M. 49, 3100 g. Ein mässiger Scheidendammriss erforderte 6 Nadeln.

Am 3.-4. Tage (27. 12.) plötzlicher Anstieg auf 39,6, P. 108. Geringe Lochialstauung. Riss nicht belegt.

Am 5. Tage 41,0, P. 140. Scheide und Portio ganz rein. Begrinnender Meteorismus. Kein Appetit. Kopfschmerzen. Blähungen spontan.

Am 6. Tage (29. 12.) 49,6, 116. Meteorismus und Leibschmerzen nebmen zu trotz Eisbeutel und Opium.

Am 7. Tage 40,0, 104. Subjectives Befinden besser; Sensorium jedoch benommen, höherer Meteorismus, aber weniger empfindlich.

31. 12. 41,0, P. 136. Da der Meteorismus noch mehr zunimmt, das Sensorium benommen bleibt und der Allgemeinzustand der Kranken sich immer mehr verschlechtert, so wird am Abend des 31. 12. 06 die Laparotomie mit nachfolgender Drainage vorgenommen.

Sowohl in der rechten als auch in der linken Inguinalgegend wird ein mit dem Lig. Poup. parallel laufender Schnitt bis in die Bauchhöhle gemacht und eine zu jedem entsprechende Gegenöffnung ungefähr $10 \mathrm{~cm}$ höher, unterhalb des Rippenbogens. Durch beide sich entsprechende Oeffnungen auf jeder Seite wird ein Gummidrain gelegt und mit Nähten befestigt, wonach noch von der in der rechten lnguinalgegend befindlichen Oeffnung ein Gummirohr durch den Douglas'schen Raum mit einer Kornzange hindurchgeführt und ebenfalls befestigt wird: Aus jeder Oeffnung, namentlich aus dem hinteren Scheidengewölbe, floss eine Menge trüben flockigen Secretes ab, das eine Menge von Streptokokken aufweist. Die Drainröhren werden nun mit ca. 10 Litern erwärmter physiologischer Kochsalzlösung so lange durchgespült, bis die Flüssigkeit ganz klar abfliesst.

Für die nächste Zeit wurde nun nach den bisher günstig verlaufenen Fällen die Weiterbehandlung so festgesetzt, dass mitten auf den Leib ein Eisbeutel gelegt, dass täglich drei Opiumpulver à 0,03 verabreicht und die Drains 2 mal täg]ich mit erwärmter sterilisirter Kochsalzlösung durchgespült wurden.

Schon in der auf die Operation folgenden Nacht trat eine Besserung ein. Die Schmerzhaftigkeit des Leibes liess nach bei zunächst noch gleichbleibenden Meteorismus.

Am 1. 1. 07 41,0, 132. Kein Erbrechen, kein Aufstossen.

Am 2. 1. 40,2, 120. Flatus spontan. Eiter.

Am 3. 1. 38,7, 120. Beim Durchspülen der Drains entleert sich

Am 4. 1. 40,3, 140. Subj. Befinden gut. Meteorismus lässt nach. Reichliche Kost.

Am 5. 1. 39,3, 120. Keine Klagen. Milch. 
Am 6. 1. 40,0, 144. Schlaf gut. Linkes Drain kaum noch durchgängig. Am Besten ist das im Douglas liegende durchzuspülen. Milch, Eier, Eleisch.

Am 7. 1. 39,1, 120 .

Am 9. 1. 38,8, 104. Entfernung des rechten seitlichen Rohres. Leib flach. Scheidenspülung mit ẗbermangansaurem Kali. Verband der Wunden mit essigsaurer Thonerde. Durchspülung der Drains mit Wasserstoffsuperoxyd.

Am 11. 1. 41,2, 120. Linksseitiges Drain entfernt. Erbrechen. Keine Leibschmerzen. Puls klein und frequent.

Am 14. 1. Spontaner Fieberabfall. Subjectives Wohlbefinden. Das im Douglas liegende Rohr wird 2 mal täglich durchgespült.

Am 19. 1. Von neuem Fieber. Beginnende Knöchelödeme. Diagnose: Beginnende Thrombose, die sich im weiteren Verlauf bestätigt. Hocblagerung der Unterschenkel.

Am 21. 1. In Gleichem. Leib weich, nirgends schmerzhaft.

Am 23. 1. lassen sich die Drainöffnungen nicht mehr durchspülen.

Vom 24. 1. an Temperatur und Puls ganz normal. Nach und nach granuliren die Wunden zu.

Am 18. 2. erstes Aufstehen. 20. 2. Wunden ganz geschlossen.

$\mathrm{Am}$ 2. 4. Entlassung im besten Wohlbefinden. Beine auch nach langem Herumgehen nicht mehr geschwollen. Die 4 Narben sehen gut aus. Schwächegefühl nicht mehr vorhanden.

Die am 3. Tage p. p. plötzlich aufgetretene schwere Erkrankung liess sich ursächlich nicht ganz aufklären und gab im Hinblick auf die bestehende Kolpitis granulosa und auf den hohen Procentsatz (10 pCt.) von frischer Gonorrhoe, unter welchem seit vielen Jahren Gebärsaal und Wöchnerinnenabtheilung der Dresdener Frauenklinik sehr zu leiden hat, Grund zu der Annahme, dass es sich auch hier, wie in den Fällen No. 4, 5, 6 und 17 der Tabelle, wohl nur um gonorrhoische Infection handelte. Am 4. Tage des Wochenbettes war die Diagnose der acuten Peritonitis sicher. Nach den bisher günstigen Erfahrungen wurde mit der bisher üblichen Behandlung von Eis und Opium nicht länger als zwei Tage gewartet, daher am 4. Tage der Erkrankung i. e. am 2. Tage der bestehenden Peritonitis die Laparotomie vorgenommen.

Es entleerte sich trübeitriges Secret mit massenhaften Streptokokken.

Eine allgemeine Besserung trat sofort ein, wenn auch 'Temperatur und Puls noch ungefähr 11 Tage lang recht hoch blieben. Am 14. Tage nach der Operation fiel die Wärme wesentlich ab; nur der noch hohe Puls deutete noch auf entzündliche Ablagerungen hin und liess eine Thrombose befürchten, die thatsächlich am 19. Tage eintrat.

Nach und nach aber schwoll das Bein ab und die Wunden 
heilten zu, sodass die Kranke, nach absichtlich langer Zurückhaltung in der Klinik, sehr gekräftigt an 2. April 07. entlassen werden konnte.

Hatte es sich in diesem Falle um eine spontane Geburt ziemlich am Ende der Schwangerschaft gehandelt und um eine wahrscheinlich schon längere Zeit vorher erfolgte gonorrhoische Infection, so bietet der nächste. Fall einen sehr vernachlässigten Abort dar, bei dem die Infection mit der allergrössten Wahrscheinlichkeit mit auf der Selbsthülfe der Frau beruht.

\section{II.}

Abortreste. Acute Peritonitis. Laparotomie bald nach Beginn derselben. Drainage. Genesung.

Frau G., 36 Jahre alt, verheirathet seit 13 Jahren, hat $5 \mathrm{mal}$ spontan rechtzeitig geboren und vor 3 Jahren eine Fehlgeburt durchgemacht. Letzte Periode Ende October 1906.

Am 15. 1. 07 sei ohne Arzt und Hebamme die Frucht abgegangen. Dabei habe sich die Frau durch Eingehen mit der Hand und Herausziehen von Frucht und Eisack selbst geholfen.

Darnach blutete Frau G. bis zum 19.1. ohne sich hinzulegen; vom 19.-21. 1. hörte die Blutung auf, wonach wieder starker Abgang yon Blut und von "Stücken" erfolgte.

Am 22. 1. Aufnahme in die Klinik mit Fieber. Es wurden hier unter Einhaltung der grössten Vorsichtsmaassregeln eine llenge Abortreste mit dem Finger aus der Uterushöhle entfernt.

Schon am nächsten Tage 38,7, 116. Sehr schmerzhafter aufgetriebener Leib. Frost. Aufstossen. Eis. Opium.

24. 1. 38,8, 108. Schmerzhaftigkeit und Meteorismus haben sehr zugenommen.

Am 25. u. 26. 1. lässt zwar die Temperatur nach bis auf 37,8 ; aber der Puls stejgt unaufhaltsam bis auf 130, ist klein, schwach. Enormer äusserst schmerzhafter Meteorismus. Zustand bedenklich. Diagnose: Peritonitis.

Daher am 27. 2. 07 Laparotomie. Schnitt in der Mittellinie. Die stark geblähten und hochroth injicirten Därme sind durch dicke eitrige Schwarten verlöthet. Beim Eingehen mit der rechten Hand entleerte sich rechts aus der Tiefe viel dünne, mit Eiterflocken gemischte Flüssigkeit.

Durchführung eines starken Gummirohres von oben durch den Douglas hindurch nach der Scheide und ebenso von der Linea alba aus je eines starken Rohres nach den Lumbalseiten, nachdem hier auf die von der Bauchhöhle her entgegengedrängte Kornzangenspitze ein Einschnitt gemacht worden war. Annähen der Drains. Durchspülung mit warmer steriler Kochsalzlösung und Vernähung der Bauchwunden soweit als nöthig.

Schon am nächsten Tage hob sich, wennn auch wenig, aber doch sichtlich das Allgemeinbefinden.

29. 1. 38,4, P. 128. Aufstossen. Neigung zum Erbrechen.

30. 1. 38,0, P. 130. Leib weniger aufgetrieben. Viel Erbrechen.

31. 1. 38,5, P. 120. 
488 Leopold, Zur operativen Behandlung der puerperalen Peritonitis.

2. 2. Fieber fällt. Leib sinkt ein.

4. 2. Leib sinkt noch mehr. Spontaner Stuhl.

10. 2. Tägliches Durchspülen der Drains.

16. 2. Kürzen der Drains.

19. 2. Drains ganz entfernt.

22. 2. Bauchwunden schliessen sich.

28. 2. Bad. Täglicher Verbandwechsel.

Am 13. 2. Entlassung.

Der Infectionsvorgang in diesem Falle liegt klar zu Tage. Ungefähr eine Woche lang lief Erau G., während der Abort im Gange war, blutend umher, also mit mehr weniger offenem Collum und holte sich schliesslich die Abgänge ron Frucht und Eisack selbst heraus.

Die Reste wurden in der Klinik mit aller Sorgfalt entfernt. Aber schon der nächste Tag bot die Symptome schwerer Erkrankung des Bauchfells dar: Fieber, hoher Puls, Aufstossen, Frost, sehr schmerzhaften aufgetriebenen Leib!

Es trat zwar Nachlass ein und täuschte eine gewisse Besserung vor.

Andauernd blieb aber der Puls klein und sehr frequent, bis am 24. 1. mit aller Macht und ganz unverkennbar die schulgerechten Symptome der Peritonitis sämmtlich vorhanden waren.

Noch kam die am gleichen Tage vorgenommene Laparotomie - glücklicherweise! - nicht zu spät. Es wäre aber in Anbetracht des langhin geschleppten Aborts, der Selbsthülfe der Frau, der persönlichen Infection und der gleich nach der Entfernung der Abortreste auftretenden schweren Krankheitserscheinungen die Vornahme der Laparotomie schon am ersten Krankheitstage (also am 23. 1.) ganz gerechtfertigt gewesen!

Der nächste Fall (No. 3) hat mit dem ersten sehr grosse Aehnlichkeit. Die Infectionsursache liess sich nicht aufklären, namentlich Gonorrhoe nicht bestimmt nachweisen, Die grosse Zahl von Frauen, welche vor und nach diesem Fall in der Klinik entbunden und glatt genesen waren, liess es aber nicht begründet erscheinen, eine in der Klinik verschuldete Infection anzunehmen.

III.

Acute Peritonitis. Laparotomie am 3. Tage der Erkrankung. Genesung.

Das 26 Jahre alte Dienstmädchen Seif. trat am 21. 2. 07 in die Klinik ein. War angeblich immer gesund. Menstruation vom 13. Jahre an, 3-4 wöch. 3-8 tägig. Herz, Lungen, Nieren normal. 
Becken: 22, $24^{1} / 2,28^{1} / 2,17$. Conj. diagon. 9; Conj. vera $71 / 2$ geschätzt. Vorberg tiefstehend. Allgemein verengtes platt-rachitisches Becken. Innere Organe noch ganz geschlossen.

Wehenbeginn am 24. 2. 07. Geburt am 26. 2. 07. 9 Uhr 40 Min. Vorm. (I. Schädellage a) durch Zange wegen mangelhafter Herztöne nach einer Dauer von 1 Tag, 13 Std., 25 Min. Kopf stand noch in Beckenmitte. Geringe Zerreissung am Frenulum. Naht. Kn. 52, 3500.

Die Kreissende war dreimal, jedesmal vom Assistenten und dem diensthabenden Externen innerlich untersucht worden. In ihren Secreten wurden nach der Aufnalıme specifische Keime nicht nachgewiesen.

Am 3. Tage p. p. (28. 2.) plötzlich $39,3,128$. In der rechten Scheidenwand ein schmierig belegter oberflächlicher Riss. Parametrien druckempfindlich. Meteorismus. Aufstossen!

1. 3. $38,4,120$ bis $40,0,124$. Schmerzhaftigkeit des Leibes und Meteorismus nehmen bei gutem Allgemeinbefinden zu. Links und rechts hinten unten am Abdomen gedämpft tympanitischer Schall. Singultus!

Abends 39,6, 132. Dämpfung hat wesentlich zugenommen. Puls andauernd gestiegen. Meteorismus noch höher. Diagnose: Peritonitis mit freier Flässigkeit in den seitlichen abhängigen Partien.

2. 3. Da der Zustand unverändert, so wird heute, also am 5. Tage des Wochenbettes und am 2.-3. Tage der Erkrankung die Laparotomie vorgenommen.

$6 \mathrm{~cm}$ langer Schnitt in der Linea alba, in der Nitte zwischen Nabel und Schamfuge. Es entleert sich viele trübbräunliche, mit Eiterflocken vermischte Flüssigkeit. Gegenöfïnungen in den beiden Flanken. Durchziehen von starken Gummidrains und Annähen ihrer Enden in den drei Wundöffnungen. Dann wird von oben her, unter Leitung des linken Zeigefingers, eine Kormzange hinter dem Uterus bis zum Douglas geführt, dieser durchstossen und von der Scheide, her ein starkes Robr heraufgezogen und mit dem Ende ebenfalls in der Linea alba-Wunde befestigt.

Schliessen der Incisionen so weit als nothwendig. Durchspülung der drei Drainröhren mit ca. 5 Liter steriler erwärmter Kochsalzlösung. Dichteste Bedeckung mit Gaze. Handtuchverband.

In der Bauchhöhlenflüssigkeit fanden sich bei sofortiger Untersuchung massenhaft Eiterkörperchen, spärliche Kokken unbestimmter Art.

Von nun an kam die gleiche Behandlung von früher zur Anwendung. Eisbeutel auf den Leib. Dreimal täglich Opium 0,03. Täglich 2 maliges Durebspülen der Drainröhren. Leichte, sehr nahrbafte Kost.

Am nächsten Tage nur 38,4, P. 112.

4. 3. Kein Erbrechen, wenig Aufstossen. Schmerzhaftigkeit des Leibes lässt nach. $38,9,124$.

6. 3. 39,0, P. 120 . Allgemeinbefinden viel besser. Leib nicht mebr gespannt, nicht druckempfindlich.

8. 3. $38,5,120$. Flatus spontan. Secretion aus den Drains sehr stark.

11. 3. $38,0,120$. Wundöffnung in der Mittellinie wird mit tief umgreifender Nadel zusammengezogen.

13. 3. $38,5,124$. Decubitus gespalten.

14. 3. $38,2,100$. Die beiden Seitendrains werden entfernt.

15. 3. $38,2,104$. Sitzt auf im Lehnstubl.

19. 3. 37,8, 112. Entfernung des Rohres im Douglas.

Von num ab tritt völlige Reconvalescenz ein, Abheilen des Decubitus und Zuheilen der drei Wundöffnungen. 
27. 3. Baden und Aufstehen. Patientin erbolt sich zusehends.

Am 26. 4. plötzlich wieder Fieber. 39,9, P. 130. Puls war seit dem 23. April in langsamem, aber stetigen Ansteigen begriffen.

Thrombose der linken Vena femoralis. Absolute Bettruhe. Hochlagerung des linken Unterschenkels. - Urin bierbram, stark eiweisshaltig. Mikroskopisch: hyaline epitheliale Cylinder, spärliche weisse. Verschiedene rothe Blutkörperchen. Acute parenchym. Nephritis.

Vom 3: 5. an Entfieberung und langsame Erholung.

Am 18. Juni Entlassung nach völliger Genesung und bei vortrefflichem Allgemeinbefinden.

Bemerkenswerth ist in diesem 3. Falle der ganz plötzliche und scharfe Ausbruch bedrohlicher Zeichen von acuter Peritonitis (Singultus und schmerzhafter Meteorismus) schon am 3. Tage des Wochenbettes! Da war auch schon in der rechten Scheidenwand ein schmierig belegter oberflächlicher Riss zu bemerken!

Beachtet man, dass in der Klinik selbstredend nur mit vorher ausgekochten Instrumenten und mit sterilisirten Handschuhen operirt wird, dass äussere und innere Genitalien vor der Operation sorgfältigst, soweit dies durchführbar ist, gereinigt werden und dass gerade die operativen Fälle erfahrungsgemäss, wegen dieser weitgehenden Vorreinigung, von den besten Wochenbetten gefolgt sind, so kann man in diesem wie in ähnlichen Fällen, in denen der sichere Gonokokkennachweis die Ursache des Fiebers klarlegte, nur annehmen, dass es sich auch hier um einen Fieberorreger gehandelt haben wird, der schon in der Schwangerschaft bezw. in den letzten Tagen vor Geburtsbeginn in die inneren Theile abgelagert worden ist; welcher Art aber derselbe war, liess sich nicht feststellen.

Wir kommen nun zu zwei Fällen von Fehlgeburt bezw. Abort, welche beide in schwer inficirtem Zustande zur Aufnahme kamen, aber durch die Laparotomie nicht mehr gerettet werden konnten.

$$
\text { IV. }
$$

Puella publica. Spontane Frühgeburt im V. Monat. Schwer inficirtübernommen. Peritonitis acuta. Laparotomie 4 Tage nach Beginn derselben. Drainage. Tod am 13. Tage. Zu spät operirt.

Am 26. $2.07 \mathrm{kam}$ die 20 Jahre alte Wie. zur Aufnahme. Menstruirt seit dem 13. Jahre, 4 wöch., 4 Tage, normal. Letzte Periode Anfang September 1906 wie gewöhnlich.

Von Mitte December 06 bis Ende Januar 07 in einem Dresdener Krankenhaus antisyphilitiseh behandelt. 
Becken: 221/2, 24, 29,0, 18,0. Uterus entspricht dem 5.-6. Monat. Herztöne rechts vorn, 150 in der Ninute.

Am Abend vor der Aufnahme hatten, nach zuverlässiger Angabe, noch 6 Männer mit der W. geschlechtlich verkehrt. In der Nacht traten Blutungen auf.

Temp. 37,6, P. 120. Wenige Stunden nach der Aufnahme wurde, ohne dass eine innere Uutersuchung erfolgt war, spontan eine schwach lebende Frucht (Knabe, $33 \mathrm{~cm}, 770 \mathrm{~g}$ ) geboren, welcher nach 1/2 Stunde die Nachgeburt von selbst nachfolgte.

Weder Blutung noch Zerreissung. Uterus fest zusammengezogen. 39,4, P. 128 bald nach der Geburt.

27. 2. 37,6, P. 103. Abends Schmerzen in der Unterbauchgegend.

28. 2. 39,8, P. 120. Collum schmierig belegt. Scheidensecret sehr übelriechend. Parametrien druckempfindlich. Singultus. Kein Erbrechen. Abends Schüttelflost. 39,9, P. 120.

Am 1. 3. Nach vorübergehendem Abfall von Temperatur und Puls zweiter Schüttelfrost. 38, כ, P. 150. Erbrechen. Leib aber nicht aufgetrieben. Pat. klagte über Schmerzen zu beiden Seiten des Unterleibes. Eisbeutel. Opium. Scheidenspülungen.

Vom 1.-2. 3. 40,4, P. 160 . Kein Meteorismus. Aber Schmerzen im Unterleib. Morphium.

Vom 2.-3. 3. Leidliches Befinden.

Am 3. 3. Vorm. bei 39,6, P. 120 Schüttelfrost. Starkes Erbrechen. Leib aber nicht aufgetrieben.

Am 4. 3. 39,8, P. 124. Leib gespannt; sebr schmerzhaft, namentlich seitlich. In den abhängigen Partien geringe Dämpfung. Singultus, Erbrechen. Diagnose: Acute Peritonitis, vielleicht schon volle 4 Tage besteliend.

Laparotomie wie im vorhergehenden Falle. Eröffnung in der Mittellinie und dann Gegenöffnungen in den Flanken und durch den Douglas'schen Raum mit Durchziehen und Aunähen von starken Gummidrains. Es entleerte sich reichliche gelbbräunliche, von Eiterflocken durchsetzte Flüssigkeit, welche eine Menge Streptokokken aufwies.

Durchspülung der Röhren mit ca. 10 Litern warmer steiler Kochsalzlösung.

Darnach 37,0, P. 98. Nachbehandlung wie in den bisherigen Fällen: Eisbeutel auf den Leib. Opium 3 mal täglich 0,03; zweimalige Durchspülung der Röhren.

Am 5. 3. früh wieder 39,8, P. 120, Kein Erbrechen noch Aufstossen. Geringe Schmerzhaftigkeit des Leibes.

Am 6. 3. 38,8, P. 116. Allgemeinbefinden schlecht. Grosse Schwäche. Leibschmerzen, trotz Opium und geringen Norphiumgaben.

Am 7. 3. 38,1, Puls bis 116. Allgemeine Schwäche. Erbrechen galliger Massen. Leib gespannt.

Am 8. 3. Icterus. Starkes Aufstossen und Erbrechen. Kalte Hände. Nimmt nichts zu sich.

Unter zunehmender Schwäche hält sich die Temp. auf ca. 38,0 und der Puls zwischen 116 and 124, bis am 11. 3. Vorm. 10 Uhr der Tod eintrat.

Section am nächsten. Tage: Bei Eröffnung der Bauchhöhle zeiğte sich die Leber nach oben und hinten gedrängt, Magen und Darmschlingen in mässigem Grade geblaht; in den seitlichen Theilen des 
Leibes und nach dem kleinen Becken zu dicke eitrige Auflagerungen, sowie einige Esslöffel voll eines ausserordentlich übelriechenden Eiters.

Zwerchfell stand beiderseits am oberen Rand der 3 . Rippe.

Bei Eröffnung der Brusthöhle sanken die Lungen wenig zurück. Auf der linken Pleura fibrinös eitrige Beläge. Herz, Herzbeutel und grosse Gefässe normal.

Lungen mässig blutreich, enthielten vorn in den Unterlappen mehrfache Abscesse, welche sich bucklig über die Oberfläche vorwölbten.

Milz $15: 7,5: 3$, fest. Die Oberfläche beider Nieren von Blutungen durchsetzt. Rinde breit, quoll auf der Schnittfäche hervor; Pyramiden braunroth.

Leber gequollen, Substanz brüchig. Schnittfläche gelb. Schleimhaut der Blase stark entzündlich geröthet.

Uterus $11: 8 \frac{1}{2}: 5 \mathrm{~cm}$. Höhle ausgekleidet mit diphtheritischen Belägen, welche besonders an der Placentarstelle stark entwickelt waren. An der hinteren Lippe der Portio ein unregelmässiger Riss von $3 \mathrm{~cm}$ Länge und $1 \mathrm{~cm}$ Breite, welcher dicht hinter dem freien Rande der vorderen Lippe endete. Uteruswand von Abscessen auf das Dichteste durchsetzt. Sie wölbten die Serosa überall hervor. Alle Gefässe mit Eiter gefüllt. Das linke und rechte Parametrium stark verbreitert und von eitrig sulzigen Massen durchsetzt. Das linke Ovarium vereitert; im rechten mehrere Abcesse.

Diagnose (Prosektor Dr. Geipel): Sepsis ausgebend von diphtheritischer Metritis und Endometritis purulenta nach Abort. Doppelseitige Parametritis, Oophoritis. Embolische Abscesse in den Lungen. Acute hämorrhagische Nephritis.

Der Eintritt der Peritonitis in diesem Falle war nicht der gewöhnliche. Daher machte auch die Stellung der Diagnose und der Anzeige zur Operation einige Schwierigkeit.

Zunächst muss auf die hohe Infectionsgefahr aufmerksam gemacht werden, in welcher sich die Kranke beim Beginn des Aborts in der Nacht vom 25.-26. Febr. 07 befand, da sie eben noch mit verschiedenen Männern geschlechtlich verkehrt hatte. Bald nach erfolgtem spontanen Abort machte sich auch schon hohes Fieber bemerkbar. 39,4 , P. 130; ebenso Schmerzen am nächsten Tage; auch am 3. Tage schon Singultus und Schüttelfrost.

Vom 1.-3. März trat eine gewisse Beruhigung ein, welche leider über die so ernsten Symptome hinwegtäuschte und eine Besserung annehmen liess. Doch hätte der unheimlich hohe und sehr kleine Puls die Schwere der Erkrankung viel schärfer in's Auge fassen müssen.

Am 3. März traten mit einem Male Schüttelfrost und starkes Erbrechen auf! und erst am 4. März schmerzhaft aufgetriebener Leib.

Nunmehr erfolgte die Laparotomie, welche Eiterflocken und trübes Serum in Menge entleerte. Aber schon 2 Tage später ver- 
fiel die Kranke und ging am 7. Tage naçh Eröffnung der Bauchhöhle an weit vorgeschrittener Sepsis zu Grunde.

In diesem Falle hätte die folgende Betrachtung maassgebend sein müssen: Die Kranke kam zur Geburt mit allen Vorbedingungen zu sofortiger Infection! Der nächste Tag bot auch schon hohes Fieber dar.

Da in den nächsten Tagen bei schwankender Wärme der Puls sehr hoch blieb und Singultus und Fröste eintraten, so wäre es richtiger gewesen, auch. Wenn Erbrechen und schmerzhafter zunehmender Meteorismus nicht festzustellen waren, doch schon am 2. Tage nach erfolgtem Aborti. e. am 28. Febr., also 4 Tage früher als geschehen, die Laparotomie vorzunehmen.

Mit grosser Wahrseheinlichkeit wäre dem Vordringen der Eitererreger bezw. ihrer Gifte im Organismus Einhalt geboten worden. Jedenfalls wäre der Eingriff nicht so schwer gewesen, als die Gefahr, in welcher sich die Wöchnerin bei Zuwarten befand.

V.

Hohes Fieber bei Abort. Ausserhalb erfolgte künstliche Verletzung im Collum. Peritonitis. Laparotomie am 2. Tage der Erkrankung. Drainage. Tod am folgenden Tage.

Frau F., 26 Jahre alt, wurde wegen seit 4 Wochen schon andauernder Schwangersehaftsblutungen, die oft von hohem Fieber begleitet wạon, der Klinik am 1. 12. 07 von ihrem Ehemanne zugeführt.

Erste Regel im 13. Jahre, 2-3 Tage mässig, stets regelmässig. alle 4 Wochen. Letzte Menstruation vor etwa 12 Wochen wie gewöhnlich. Seit 4 Wochen hat Frau F. fortwährende zwar geringe, aber, namentich durch das hinzugetretene Fieber sehr angreifende Blutungen, die $a b$ und zu geringer und stärker waren, bis plötzlich am 1. 12. Abends eine sehr starke Blutung mit Abgang von grösseren festen Stücken eintrat. Seit 4 Wochen klagte Frau F. auch über heständige Uebelkeit. bringen.

Ein hinzugerufener Arzt tamponirte und liess Frau F. in die Klinik

Allgemeinzustand gut. Herz nach rechts verbreitert. Spitzenstoss noch 1 Finger breit ausserhalb der Mammillarlinie fühlbar. Systolisches Geräusch an der Herzspitze und über der Pulmonalis. Zweiter Spitzenstoss verstärkt. Leib weich, nicht druckempfindlich. Entfernung der Tamponade. Sorgfältige Reinigung der Scheide.

Cterus vergrössert, beweglich. Portio in der Mittellinie, Muttermund kanm für einen Finger durchgängig.

Nach genügender Erweiterung des Collum mitteis Laminaria unter Beachtung aller Vorsichtsmaassregeln wurden am 4.12.07 aus dem Uterus noch mebrere Placentarreste entfernt, worauf die Blutung stand. 
An demselben Abend bereits 39,5, P. 108. Geringe Blutung. Leibschmerzen. Eisbeutel. Opium. Morpbium.

Am 6. 12. 39,9, P. 128. Leib gespant, druckempfindlich. Uebelriechendes Scheidensecret. Etwas Brechreiz. Einstelluug: Schmutziger übelriechender Belag an der Portio: betupft mit 5 proc. Carbollösung. Cavum uteri ausgespült mittels dünnen Katheters mit 50 proc. Alkohol. 39,9, P. 132.

Am 7. 12. 39.4-40, P. 128-136. Grosse Schwäche. Icterus. Leib vom Nabel abwärts gespannt und sehr schmerzhaft. Erbrechen. Singultus.

Abends 5 Uhr. Zustand bedeutend verschlimmert. Leib sehr stark gespannt. Im Ganzen besonders über dem linken Hypogastrium druckempfindlich. Ueber dem linken Poupart'schen Bande eine handbreite Dämpfung. Diagnose: Acute Peritonitis mit linksseitigem vielleicht abgekapseltem grösseren Eiterherd.

Laparotomie wie gewöhnlich. Eröffnung in der Mittellinie und in den beiden Flanken sowie im Douglas'schen Raume. Durchziehen und Annähen von 3 starken Gummiröhren und Durchspülung derselben. Es entleert sich eine reichliche Menge flüssigen und flockigen Eiters (Streptokokken). Die linke Tube liegt in einer grossen Abscesshöhle, welche beim Eingehen mit der linken Hand, um das Drainrohr durch den Douglas zu führen, eröffnet und entleert wird. Beide Tuben stark verdickt und vergrössert.

Während der Operation war der Puls kräftig; eine Stunde nach derselben war er schwächer geworden. Wärmezufubr. Kochsalz. Kampher.

Am 8. 12. tritt schneller Verfall der Kräfte ein und bereits in der folgenden Nacht um 2 Uhr der Tod.

Die Section (Prosector Dr. Geipel) klärte die bisher nicht nachzuweisende Ursache der ganz akut entstandenen und schnell zum Tode führenden Peritonitis dadurch auf, dass sich im Collum eine Verletzung vorfand, die nur ausserhalb der Klinik und zwar höchstwahrscheinlich mit dem spitzen Ansatzohr einer zu Zwecken der Abtreibung viel verbreiteten Spritze beigebracht sein konnte.

Aus dem Sectionsprotokoll sei folgendes Wesentliche hervorgehoben:

Leber stark nach hinten und oben gedrängt. Darmschlingen gebläht und verklebt durch dicke grünlichgelbe Eiterablagerungen. Bauchfell trüb, stellenweise stark injicirt.

Pleurablätter glatt spiegelnd; ebenso Herzbeutel. Herz und Lungen in der Hauptsache normal.

Milz 16:8:4 cm. An beiden Nieren Rinde getrübt.

Uterus $10: 5: 3,5 \mathrm{~cm}$. Collum und Corpushöhle belegt mit ziemlich zähem Eiter. In der hinteren Collumwand, ungefähr $6 \mathrm{~cm}$ oberhalb des äusseren Muttermundes, befindet sich ein $4-5 \mathrm{~mm}$ breites, $7 \mathrm{~mm}$ tiefes rundliches mit Eiter angefülltes Loch, welches nicht die Collumwand durchdringt, das aber nach seiner ganzen Beschaffenheit nur künstlich beigebracht sein kann.

Im rechten Parametrium sulziges Infiltrat. Durchschnitte durch die Uteruswand ergeben nirgends eine Füllung der Lymphgefässe bezw. der Gewebsspalten mit Eiter.

Der Schwerpunkt für die Aetiologie der Infektion rubt hier auf zwei Thatsachen: erstens auf der ausserhalb erfolgten Collum- 
verletzung, deren zeitliche Entstehung ganz unaufgeklärt blieb und zweitens auf den fast 4 Wochen lang bestehenden, vernachlässigten Abortblutungen. Ob letztere die Folge der Collumverletzung waren, liess sich nicht feststellen. Höchstwahrscheinlich aber baben beide Thatsachen, Verletzung und Blutungen, sich in ihren Wirkungen vereinigt und die Gefahr von Tag zu Tag gesteigert. Leider kam die Verletzung vor dem Tode nicht zu unserer Kenntniss, war auch bei der Einstellung garnicht sichtbar.

Wie dem aber auch sei, heute stehe ich nach hinlänglicher Erfahrung auf dem Standpunkte, dass man diesem Falle viel energischer entgegengehen musste. Bekanntlich sind langandauernde Abortblutungen als Infektionspforten immer hoch gefährlich. Nun kommt eine ausserhalb erfolgte Tamponade hinzu, (nach dem am 1. 12. eine sehr starke Blutung mit Abgang von grösseren Stücken eingetreten war), eine Maassnahme, die nur zu häufig eine schon bestehende Infektion noch verschlimmert hat! Also die Kranke musste bei ihrem Eintreten in die Klinik als ganz besonders gẹfährdet betrachtet werden! Wenn nun nach der Entfernung der Placentarreste, welche selbstverständlich unter den denkbar grössten Vorsichtsmaassregeln geschah, schon an demselben Abend hohes Fieber beobachtet wurde, verbunden mit Leibschmerzen, dem schon am nächsten Tage Meteorismus folgte, so hätte der ganz ungewöhnlich schnelle Eintritt der Peritonitis deshalb besonders ernst genommen werden und deshalb schon jetzt die Laparotomie verlangen müssen, weil eben bereits wochenlange Blutungen. und wochenlang bestehende Infektionsmöglichkeiten vorangegangen waren.

Man wird sich also in solchen Fällen immer zu fragen haben: "Ist die Gefahr, in welcher sich die Wöchnerin augenblicklich befindet, schlimmer, als die Gefahr sein würde, welche eventuell mit einer Laparotomie verbunden ist?" Die Antwort kann dann in einem Falle, wie dem vorliegenden, nur so lauten, dass die beginnende Peritonitis weit gefahrdrohender ist und dass jede Verzögerung mit dem Eingriff sehr verhängnissvoll werden kann.

Es bedarf wohl keiner Erwähnung, dașs auch in der Laparo. tomie eine unbedingt sichere Hülfe nicht erblickt werden kann. Denn wer kann vorausgegangene kriminelle Verletzungen und die schleichende Verbreitung ihrer Infektionsmassen immer erkennen? Sie kann also auch bei recht früher Vornahme doch schon 
zu spät kommen, und man würde bei kriminellen Verletzungen, falls sie wirklich baldigst erkannt wurden, die Frage besser so stellen, ob eine Entfernung des ganzen Uterus von der Scheide aus mit Drainage der Beckenböhle, bei drohenden Symptomen, nicht die viel richtigere Maassnahme als die Laparotomie wäre, mittels welcher nur die Eitermassen abgelassen werden?

Bevor wir uns nun zur puerperalen Metrophlebitis wenden, empfiehlt es sich, die 11 Fälle operativ behandelter puerperaler Peritonitis (s. Tabelle) einer gemeinsamen Betrachtung zu unterziehen.

Von den 11 Frauen waren 5 Erstgebärende (Nr. 1, 2, 7, 9, 10) und 6 Mehrgebärende (Nr. 4, 5, 6; 3, 8, 11).

Von den Erstgebärenden war die Frau in Nr. 1 mit voller Sicherheit, die Frauen 7 und 9 mit grosser Wahrscheinlichkeit gonorrhoisch inficirt worden; die Frau No. 10 kam zweifellos inficiert (puella publ.) ebenso die carcinomatöse No. 2 inficirt zur Entbindung. Demnach trugen 3 von diesen 5 Erstgebärenden mit voller Sicherheit das Infektionsmaterial schon in sich, 2 mit sehr grosser Wahrscheinlichkeit.

Von den 6 Mehrgebärenden war bei 3 Frauen (No. 4, 5, 6) die Gonorrhoe mit voller Sicherheit zugegeben bezw. festgestellt. Die drei anderen (No. 3, 8, 11) mit Abortresten eingelieferten kamen schwerkrank bezw. hoch fiebernd zur Klinik.

Demnach waren 9 von diesen. 11 Gebärenden mit voller Sicherheit, 2 von ihnen mit grösster Wahrscheinlichkeit, schon vor der Geburt inficirt.

Von allen 11 Frauen war nur eine während der Entbindung innerlich nicht untersucht worden (No. 4). Sie war aber von ihrem Ehemanne kurz vor der Conception gonorrhoisch inficirt worden und erkrankte unter hohem Fieber am 5. Tage des Wochenbettes an akuter Peritonitis.

Gruppirt man diese 11 Fälle nach dem zeitlichen Ausbruche der schweren Erkrankung, so kamen mit hohem Fieber und den Zeichen schwerer Infektion zur Geburt die Frauen 3, 8, 10, 11, sämtlich abortirend.

Schon am 2. - 3. Tage p. p. trat sehr hohes Fieber auf bei No. 2 (Carcinom des Rectum), bei No. 5 (sicher Gonorrhoe)

bei No. 7 und 9 (höchstwahrscheinlich Gonorrhoe).

und erst am 5. - 7. Tage p. p. als Spätfieber bei No. 1 (am 
2. Tage), bei No. 4 (am 5. Tage) und bei. No. 6 (am 6. Tage). Diese 3 Wöchnerinnen waren vor bezw. in der Schwangerschaft gonorrhoisch inficirt worden.

Von grösster Bedeutung ist natürlich dio sichere Diagnose der Peritonitis, von welcher allein die Anzeigestellung zur operativen Behandlung abhängt.

Von allen Symytomen kommt der Puls in erster Linie in Betracht. Der bei einer gesunden Wöchnerin ruhige, kräftige und volle Pulsschlag von $80-70-60$ in der Minute wird entweder langsam kletternd oder in wenigen Stunden klein, frequent, unruhig, $112-120$, ja selbst noch kurzer Zeit schon 140 in der Minute befunden, wobei die Temperatur noch ganz normal, das Allgemeinbefinden noch ein ganz ungetrübtes sein kann.

Aber bald tritt schon ein gewisses Unbehagen hinzu: Kopfschmerz oder etwas verminderter Appetit, manchmal auch unbestimmter Schmerz in der Unterbauchgegend, als Darmkolik von der Kranken gedeutet, bis der aufmerksamen Pflegerin oder dem Arzte der erstmalige Singultus als ganz bedenkliches Zeichen auffällt. Wiederholt waren diese beiden Symptome: schnell steigender Puls und mehrmaliger, bald wieder aufhörender Singultus die einzigen Vorboten der gefahrvollen akuten Erkrankung.

Wir messen ihnen daher, mögen sie allein oder gemeinsam auftreten, eine sehr grosse Bedentung bei und sehen in den weiter hinzukommenden Krankheitserscheinungen: dem zunehmenden Leibschmerz und Meteorismus, der Dämpfung in den seitlichen Parthien des Leibes, der steigenden Temperatur, dem sich verschlechternden Allgemeinbefinden nur eine Bestätigung unserer Annahme, dass die Kranke schwer inficirt ist. Wir machen daher die $\mathrm{Be}$ testigung unserer Diagnose nicht davon abhängig; ob diese letztgenannten Symptome noch hinzukommen. In der Regel folgte dem hohen, frequenten, leicht unterdrückbaren Puls und dem Singultus eines oder mehrere jener Symptome so schnell nach, dass zu der Abrundung des Gesammtbildes der puerperalen Peritonitis thatsächlich nichts mehr nothwendig war.

$J_{a}$ man kann sogar für jeden einzelnen Krankheitsfall gewissermassen von einer Permutation der Erscheinungen sprechen, unter denen immer wieder der unheimliche Puls, der Singultus und der mehr oder weniger gespannte, nicht immer empfindliche Leib die wichtigste Rolle spielen.

Soll man sich nun sanguinisch der Hoffnung hingeben, diese 
ganz ernsten Krankheitserscheinungen, welche in $24-48$ Stunden zum Tode führen können, mit Eis, Opium, mit Antistreptokokkenserum oder anderen Mitteln bekämpfen und zu nichte machen zu können?

Hier hat man sich allen Ernstes der Befunde zu erinnern, die uns soviele Sectionen und auch schon genügend viele Operationen gelehrt haben!

Führt man nämlich schon am 2. Tage nach Ausbruch der Peritonitis die Laparotomie aus, so ist man erstaunt, wieviel Eiter und trübe Flocken schon in der Bauchhöhlenflüssigkeit herumschwimmen und eine wie enorme Masse ron Gono- und Streptokokken in ihr nachzuweisen sind! Welches Mittel aber könnte diese Eitererreger und ihre Toxine abtödten? Und wer vermag in jedem einzelnen Falle mit voller Sicherheit zu sagen, hier waren nur Gonokokken, hier nur Streptokokken, hier nur Bacterium coli etc. die Eitererreger, um das entsprechende, auch sicher wirkende Mittel auswählen zu können?

Nach meinen bisherigen Betrachtungen stelle ich demnach die Diagnose der akuten puerperalen Peritonitis dann als gesichert hin, wenn der bisher ruhige Puls langsam oder schnell steigt und von nun ab auf einer für eine Wöchnerin ganz abnormen Höhe bleibt (100-- $120-140$ in der Minute); wenn hierzu ein oder mehrere Male Singultus kommt, wenn Erbrechen grüner, galliger Masșen auftritt; wenn dann Leibschmerz und Meteorismus sich bemerkbar machen, das Allgemeinbefinden leidet, Kopfschmerzen, trockene Zunge, Gesichtsverfärbung hinzukommen und zunehmende Spannung des Leibes mit Dämpfung in den Seiten das Krankheitsbild vervollständigen.

Dann aber darf man nicht mehr warten! Die Gefahr, in welcher sich die Kranke dann befindet, ist eine ganz ausserordentlich grosse, und ist ohne den geringsten $Z$ weifel eine viel, viel grössere als die Gefahr ist, in welche die Wöchnerin etwa durch die Laparotomie gebracht werden könnte.

Hieraus geht unwiderleglich hervor, dass der Zeitpunkt für die Laparotomie dann gekommen ist und ihre Vornahme nicht verabsäumt werden darf, sobald die Peritonitis 1-2 Tage besteht. Jeder weitere Tag trübt die Prognose! Denn nach 2 Tagen schon kann der Leib voll Eiter sein; die Därme können schon so untereinander verklebt sein, dass die Eröffnung des Leibes alle Ablagerungen des Eiters nicht mehr erreicht, und die Gifte der spe- 
cifischen Keime haben das. Blut und die lebenswichtigen Organe bereits derart überschwemmt, dass die Therapie sich nicht mehr gegen die Eitermassen, sondern gegen die Entgiftung des Gesammtorganismus zu wenden hätte.

Ist aber der Letztere von den Produkten der Eitererreger schon überwältigt, dann freilich wäre die Laparotomie eine für den ganz geschwächten Körper viel zu gefahrvolle Maassnahme. Hiẹr würde der obengenannte Satz umgekehrt lauten müssen: Die mit der Laparotomie verbundene Gefahr ist nunmehr für die dem Tode fast verfallene Kranke viel zu gross und darf nunmehr, weil sie viel zu spät kommt, nicht mehr vorgenommen werden.

So ergiebt sich die klare und $z$ wingende Anzeigestellung für die Laparotomie ganz von selbst aus dem Nachweis einer Peritonitis, welche seit 24 , höchstens seit 48 Stunden besteht, einem Zeitpunkt, an welchem die Krankheit noch verhältnismässig frisch ist, an welchem die Toxine der Eitererreger den Gesammtorganismus noch nicht vergiftet haben, wo der Körper der Kranken noch die nothwendige Kraft zur Selbsterhaltung hat, und die Peritonitis selbst, nicht aber der operative Eingriff die für die Kranke weit grössere Gefahr in sich einschliesst.

Was nun die Operation betriflt, so richtet sie sich nach der Art der Dauer und der Ausbreitung der Erkrankung. In allen Fällen wurde von der Linea alba aus der Douglas'sche Raum eröffnet, in einzelnen Fällen ausserdem noch die seitlichen Partien des Leibes an 2 bezw. an 4 verschiedenen Stellen.

Handelt es sich wie im Fall 2 um eine Zertrümmerung bezw. Aufbruch eines Carcinomherdes mit Einbruch in den Douglas'schen Raum und sich sofort anschliessender schwerer Bauchfellentzündung, oder wie im Fall 3 um Peritonitis post abortum, so musste natürlich zunächst die Unterbauchgegend von der Linea alba aus eröfnet und ein Drainrohr durch den Douglas gelegt werden. Da man die Entzündung noch auf die Serosa der Beckenhöhle im Wesentlichen beschränkt fand, so genügte die gründliche Reinigung derselben, der Abschluss nach oben hin durch Aneinandernähen der darüber liegenden Organe und eine Drainirung der retrouterin gelegenen Eiterhöhle nach dem Douglas'schen Raume hin.

Anders lagen die Verhältnisse in den Fällen $5-9$, wo man die Entzündung trotz früher Vornahme der Operation schon über dio ganze Bauchhöhle ausgebreitet fand. Hier wurden auch noch 
die Flanken eröffnet und Drainröhren von da aus zur Linea albawunde herausgeleitet, so dass also gleichzeitig drei Abzugs- bezw. Durchspülröhren vorhanden waren. Andererseits wurde, wie im Fall 6, die Bauchhöhle in jeder Flanke mittels je zwei Schnitten und ausserdem noch der Douglas'sche Raum eröffnet und durch sämmtliche Oeffnungen Drainröhren gezogen und eingenäht. Jede derartige Maassnahme richtete sich nach den Befunden des einzelnen Falles.

Jedenfalls wurden stets die Röhren solange mit warmer steriler physiologischer Kochsalzlösung durchgespült, bis die Flüssigkeit ganz klar abfloss. Die Durchspülung wurde dann im Wochenbett täglich $2 \mathrm{mal}$ wiederholt und zwar solange bis Temperatur und Puls sich beruhigten, das Allgemeinbefinden sich hob und die Sekretion aus den Drains nachliess.

Dass daneben alle anderen Symptome entsprechend behandelt wurden, bedarf keiner weiteren Ausführung.

Wenn nun von den 11 Operirten vier gestorben sind, so müssen die vier Todesfälle jeder für sich betrachtet und gewürdigt werden. Bei der im Jahre 1899 an Frau Fr. vorgenommenen Erstlingsoperation (No. 1), welche leider nicht mehr zum Ziele führte, wurden die wichtigsten Erfahrungen gesammelt. Der Eingriff erfolgte erst am 5. Tage der schweren Erkrankung, also viel zu spät. Die Kranke hatte bereits einen kleinen Puls von 140 Schlägen, Delirien, Erbrechen, Durchfall, hohen Leib und pleuritische Reibungsgeräusche. Die parametranen Lymphbahnen strotzten voll Eiter! Hier musste die Operation um mindestens drei Tage früher einsetzen, eine Erfahrung, welche den Fraven No. 2 und 3 zu Gute kam.

Bei der Behandlung des Falles No. 4, welcher leider auch mit dem Tode endete, schwebte uns die Nutzanwendung dieser Erfahrung selbstverständlich immer vor Augen. Aber die klinische Beobachtung der Kranken klammerte sich immer an die vorwiegend schwere Erkrankung der rechten Adnexe, während als das wesentlichste Krankheitsmoment $\operatorname{der}$ vom 2. Tage p. p. ab kleine hohe Puls, der Leibschmerz und der Meteorismus auf die Allgemeininfektion hätten hinweisen sollen. Als nunmehr die Operation vorgenommen wurde, nachdem Delirien und hohe Schwäche des Körpers eingetreten waren, da erlag der Organismus: Jetzt freilich war dic Operation gefährlichẹ, als dic Krankheit selbst. Sic hätte 3 Tage früher zur Ausführung kommen müssen!

Dieser Erfahrung verdanken die Kranken 5-9 ihre Genesung, 
da die Laparotomie am 2. - 3. Tage nach. Ausbruch der Peritonitis vorgenommen wurde.

Einer besonderen Erörterung bedürfen die Fälle 10 und 11, w.elche trotz vollster Beachtung der gewonnenen Grundsätze dennoch tödlich endeten.

Bei der Puella (No. 10) war der Verlauf der Erkrankung nicht der typische, daher setzte der Eingriff, obwohl seine Nothwendigkeit immer vorschwebte, doch zu spät ein. Nach dem Sectionsergebniss wäre er schon am 2. Tage post abortum am Platze gewesen, als die ersten Schüttelfröste an den Ernst der Krankheit mahnten. Somit lag die zu späte Wahl des Tages leider an der Eigenart des Verlaufes, aus welchem von nun ab die Warnung hervorgehen muss, dass hoher Puls, Singultus und Frost am 2. Tage p. p. Zeichen schwerster Infektion and Anzeigen zu operativer Hülfe sind.

Im 4: Tadesfall (No. 11) setzte diese Hülfe zeitlich richtig ein. Nach dem Sectionsergebniss aber (künstliche Verletzung im Collum) hatte die Infection soweit schon den Organismus überschwemmt, dass auch durch eine operative Entlastung die Vergiftungsfolgen nicht mehr zu beseitigen waren.

\section{Zur operativen Behandlung der puerperalen Thrombophlebitis.}

In der früheren Arbeit (Dieses Archiv 78, I.) hatte ich über einen Fall von Metrophlebitis purulenta puerperalis berichtet, bei welchem der Eiterherd und die vereiterten Thromben leider zu spät aufgesucht wurden, worauf der tödtliche Ausgang des Falles zurückgeführt werden musste.

Schwer inficirt, nach vier Tage langem Kreissen trat Frau R. (No. 12 der Tabelle) am 7. 11. 1903 in die Klinik ein. Bei den Wehen floss aus der Scheide höchst übelriechende, eiterähnliche Flüssigkeit und p. p. eine grosse Menge sehr übelriechenden Fruchtwassers. Schon am nächsten Tage machte sich hohes Fieber, am Tage darauf eine Entzündung der rechten Vena femoralis mit Schüttelfrost bemerkhar. In den folgenden Tagen entwickelte sich unter hohem, zum Theil pyämisehen Fieber, eine rechtsseitige Beckenphlegmone, deren Eiterherd endlich am 16.-17. Tage p. p. operativ aufgesucht werden sollte. Es gelang auch, ihn zu finden. Die viel zu, sehr geschwächte Kranke erlag aber dem Eiterfieber.

Von grösster Bedeutung waren einzelne Befunde bei der Section: Dic obcrflïchlichen Venen in der rechten Schenkelbenge 
waren von Thromben erfüllt, die im Centrum in eitriger Schmelzung begriffen waren.

Ferner war jetzt schon (also am 17. Tage p. p.) die untere Hohlvene von einem Thrombus angefüllt, welcher ungefähr bis zur Höhe des Zwerchfells reichte. Er haftete der Wand locker an und war in seiner Mitte eitrig eingeschmolzen, sodass nur stellenweise eine schmale Randzone übrig geblieben war.

Bei der strengen Kritik des Falles setzte ich damals auseinander, dass der operative Eingriff schon am 3. Tage p. p. erfolgen musste. "Und was hatte man aufzusuchen bezw. zu entfernen? In erster Linie die entzündeten, mit Eiter gefüllten Venen der Inguinalgegend; dann hätte man die Bauchhöhle eröffnen müssen, wo man auf das in Vereiterung begriffene Ovarium, den Ausgangspunkt der Peritonitis gelangt wäre. Der jeweilige Befund hätte dann über die Entfernung desselben bezw. über Drainage entschieden. Auch hätte sich hierbei wohl übersehen lassen, ob die Vena spermatica interna schon mit Eiter erfüllt war und die Entfernung oder nur die centrale Abbindung benöthigt hätte."

Die bei diesem Fall gewonnenen Erfahrungen blieben mir so in das Gedächtniss eingeprägt, dass sie bei einer geeigneten Gelegenheit zur Nutzanwendung dienen sollten.

Es geschah dies im nächsten Falle, dessen Rettung wohl nur der Aufsuchung und Entfernung der thrombosirten Vena spermat. int. dextra $z u$ danken ist.

VI.

Nehrgebärende. Spontangeburt. Venöse Form des Puerperalfiebers vom 9. Tage an. Doppelseitige Thrombose der Venae femorales. Später Schüttelfröste. Am 40. Tag transperitonale Entfernung der thrombosirten rechten Vena spermatica. - Genesung.

Am 19. 12. 07 suchte die $25^{\circ}$ Jahre alte geschiedene Schi. die Klinik auf.

Menstruation vom 16. Jahre, 4 wöch. 3 Tage lang; schwach. Letzte Regel Anfang April 07 3 Tage wie gewöhnlich. $\mathrm{Zu}$ Begion der Schwangerschaft viel Ausfluss.

Bisher drei spontane Geburten, Wochenbetten fieberfrei. Herz, Lungen, Nieren o. B. An beiden Beinen starke Varicen.

Becken: 23, 26, 36,5, 18,6. Vorberg nicht erreichbar. 9. Monat. 2. Schädellage.

Wehenbeginn am 19. 12. früh. $36,6,84$. Am 20. 12. 08 früh Frösteln und Fieberschauer. 38,5, P. 118. Abends 38,8. Muttermund vollständig. Nachm. 2 Uhr 25 M. Spontane Geburt eines kräftigen Knaben $(49 ; 3000)$, dem 10 Minuten später die Nachgeburt von selbst folgte. Während der $1 \mathrm{Tag}$ und 4 Stunden dauernden Geburt war die 
Sch. 2 mal und zwar im Ganzen von 4 Personen innerlich untersucht worden.

Die ersten 8 Tage des Wochenbettes verliefen vollkommen normal.

Am 9. Tage (28. 12.) früh plötzlich 40,2, P. 116. Allgemeinbefinden gestört; dabei Leib nicht druckempfindlich; Verdaunng. Brüste in Ordnung. Lochiometra. Nach Spreizen des Collum fliesst eine grosse Menge zurückgehaltenen Lochialsekretes aus. Uterusspülung mit 50 proc. Alkohol.

Am 29. 12. 39,6, P. 80 .

Am 31. 12. (12. Tag.) 39,5, P. 132. Fortwährender Kopfschmerz. Nachmittags leichte Fröste. Herpes an der rechten Unterlippe.

Am 1. 1. 08. 39,5, P. 108. Hustenreiz. Stiche in der rechten Seite beim tiefen Atemholen.

Am 2. 3. 08 . 36,0, P. 80. Rechts hinten unten Dämpfung, Reibungsgeräısche, abgeschwächtes Atbmen. Brustpriessnitz. Morphium.

Am 3. 1. 38,7, P. 90 . Dämpfung und abgeschwächtes Athmen auch links hinten unten.

Am 4. 1. 39,4, P. 98. Kopfschmerzen. Zeitweises Seitenstechen. Anschwellung des linken Beines.

Am 6. 1. 39,8, P. 114. Lungenbefund im Gleichen. Ueber beiden Oberlappen rauhes Athmen und abgeschwächtes in den abhängigen Parthieen. Wochenfluss schleimig, nicht übelriechend. Leib weich, nicht druckempfindlich.

Am 8. 1. 39,8 P. 104. Parametrien frei. Lungenbefund dasselbe.

Am 10. 1. 39,7, P. 102 . Guter Schlaf und Appetit. Auch am rechten Fuss Oedeme. Abdomen weich. Uterus nicht druckempfindlich. Im Sekret Gonokokken nicht nachgewiesen. Urin normal.

Am 14. 1. (25. Tag.) 39,6, P. 106. Befinden im Gleichen. Linkes Bein im Ganzen geschwollen.

Am 16. 1. 40,2, P. 104. Leichter Meteorismus. Beide Beine geschwollen.

Am 19. 1. (30. Tag.) 38,7, P. 108. Schwellung des rechten Beines nimmt zu. Lungenbefund noch der gleiche.

Von jetzt an pyämische Temperatur und Pulskurve.

Am 22. 1. 39,7, P. 92 . Allgemeinbefinden auffallend gut. An der Herzspitze und an der Mitralis erster Ton unrein.

Am 24. 1. 38,5, P. 108. Eine beabsichtigte intravenöse Collargolinjection von $10 \mathrm{ccm}$ musste aufgegeben werden, da bei der hohen Anämie der Kranken sich eine Vene an der Hand oder am Arm nicht füllen wollte. Dafür wurden $5 \mathrm{~g}$ subkutan in den Handrücken injicirt.

Am 26. 1. (37. Tag.) 39,6, P. 96. Nachts Schüttelfrost von $1 / 2$ stündiger Dauer. $10 \mathrm{cem}$ Collargol ins Rectum. Abdomen weich, schmerzlos. Beide Beine stark geschwollen; unterhalb der Poupart'schen Bänder die Venae fem. als fast fingerdicke Thromben zu fühlen. Leukocyten 9062 in $1 \mathrm{cmm}$.

28. 1. 40,4, P. 114. Allgemeinbefinden verschlechtert. Von Seiten der Athmungsorgane oder Genitalien keine Beschwerden. Herzgeräusch in Gleichem. Der Gesammteindruck der einer schwer Pyämischen. Weisse livide Farbe. Enorme Schwäche. Abends Kältegefühl.

Am 29. 1. 08. Da alle bisher angewandten Verfahren zu keiner Besserung geführt haben, und da anzunebmen war, dass die Fröste und das erneute sehr hohe und pyämische Fieber auf Nachschübe von vereiterten Venenbröckeln beruhte, so wurde beschlossen, den Thrombus aufzusuchen bezw, die thrombosirte Vene zu entfernen. 
Laparotomie am 40. Tage des Wochenbettes. Nach einem bis zum Nabel reichenden Medianschnitte wurden die Beckenvenen der Reihe nach sichtbar gemacht. Beide Venae iliacae externae bezw. femorales zeigten sich als ganz starke, fest thrombosirte Gefässe bis ungefähr zur Kreuzung mit den Ureteren. Schienen in voller Organisation befindlich. Die linken Venae uterinae und die linke Vena spermatica von Blut strotzend gefüllt, dunkelblau, aber ganz weich, leicht zusammendrückbar, jedenfalls ohne nachweisbare Thromben. Dagegen fühlte man die rechte Vena spermatica vom Abdominalende der Tube an bis herauf fast zur Einmündung in die Vena cava als festweichen Strang, (wie einen mittelstarken Bleistift, (Thrombus), der sich zwar zusammendrücken liess, aber dabei einen gewissen Widerstand bot.

Nach Spaltung der Peritoneums wurde die thrombosirte Vene freigelegt und oben in der Nähe der Einmündungsstelle bei der Vena cava zweimal unterbunden und in der Mitte durchtrennt. Dabei blieb freilich unentschieden, $o b$ und wieviel hier. ron dem Thrombus in die Vena cava etwa hereinragend sitzen blieb.

Nach dem Uterus hin wurde die Vena sperm., da sich der Thrombus bis dicht an die rechte Uteruskante hin erstreckte, mitsammt dem Ovarium und der Tube dieser Seite abgebunden und das Stumpfende mit dem Paquelin verschorft.

Nun wurde der Bauchfellschlitz mit fortlaufender Catgutnaht vereinigt und dann der Leib gescblossen.

Die festen Thromben der Venae femorales blieben deshalb unberührt, weil sie sich ganz hart und 'derb anfühlten, auch die beiden Beine in Abschwellung begriffen waren.

Am 30.1. 39,9, P. 116. Allgemeinbefinden wie mit einem Schlage besser. Puls kräftig regelmässig.

Am 31. 1. 38,8, P. 124. Kein Leibschmerz. Beine schwellen ab.

Am 2. 2. Langsamer Abfall von Temperatur und Puls. Wunde reaktionslos.

Am 6. 2. 38,8, P. 112. Verbandwechsel.

Am 8. 2. 39,7, P. 100 . Leib weich. Appetit noch mässig. Leukocyten 8262.

Am 10.-17. 2. Fast fieberfrei.

Am 18. 2. Plötzlich 39,8, P. 112. Blutiger Urin.

Am 20. 2. 39,3, P. 100. Befinden gut.

Vom 23. 2. Fieberfrei. Patient stand am 7. 3. auf, erholte sich zusehends und wurde am 10. 3 . entlassen.

Was lehrt nun dieser Fall? Frau Schi. deren Entbindung ganz normal verlief, aber etwas länger als gewöhnlich dauerte, hatte schon unter der Geburt 38,8 und 118 P., Frösteln und Fieberschauer gehabt. Nach normalem Verlauf von 8 Tagen setzte am 9. Tage plötzlich Spätfieber mit 40,2 und 116 P. ein, das auf Lochiometra zurückgeführt wurde. Aber es entwickelte sich von nun ab unter Kopfschmerz, Frösteln und Hustenreiz eine rechtsseitige, später linksseitige Pleuritis bezw. Pleuropneumonie, welche, als am 16. Tage sich eine Thrombose der linksseitigen 
Vena femoralis herausstellte, nur anf embolischer Basis beruhend angesehen werden konnte.

Am 22. Tage trat auch Schwellung des rechten Beines hinzu.

Am 28. Tage waren beide Beine prall geschwollen. Von nun an trat das ausgesprochene Bild der Pyämie immer mehr hervor. Abends hohe Temperatur und hoher Puls, morgens Nachlass. Schlechtes Allgemeinbefinden. Kein Appetit, hohe Anämie, grosse Hinfälligkeit, als plötzlich am 37. Tage bei vollkommen schmerzlosem Leibe noch Schüttelfröste hinzukamen.

Wer jetzt die Kranke sah, mit den stark geschwollenen Beinen, in dem ganz elenden Zustande, mit dem fliegenden Pulse, bei offenbarem Versiegen der Kräfte, unter dem Einflusse von Schüttelfrösten, der konnte zu keiner andern Ueberzeugung kommen, als dass in der Fortsetzung der Becken- oder der Beinvenen nach oben hin lockres Thrombenmaterial sitzen müsse, in eitriger Schmelzung begriffen, welches $a b$ und zu losbröckele und in die Lungenarterienzweige weiter transportirt werde.

Jetzt konnte die Fragestellung nur so lauten:, "Wie lange soll man den Frösten noch zusehen, bei entsprechender Palliativbehandlung, oder soll man gleich eingreifen?" Die Entscheidung fiel für das Letztere aus, und mit Recht, wie Operation und Verlauf bewiesen haben.

Denn die rechte Vena spermatia interna zeigte sich vom Abdominalende der Tube an bis zur Cava herauf als ein weicher, noch nicht festthrombosirter Strang, dessen ganze Beschaffenheit auf weiche, bröcklige Thrombenmassen hinwies. Deshalb wurde diese Vene von ihrer Einmündungsstelle in die Cava an bis zum Uterus hin mit dem rechten Ovarium und der rechten Tube abgebunden und entfernt, wonach in den nächsten Tagen auch sofort ein allgemeiner Umschwung in dem Befinden der Kranken mit allmählichem Ausgang in Genesung eintrat.

Die Untersuchung der entfernten Theile ergab Folgendes:

Die rechte Tube ist $4 \mathrm{~cm}$ lang geschlängelt, injicirt, Fimbrienkranz geschwollen, Lumen offen. Rechtes Ovarium mandelgross, von glatter Oberfläche, grauweisser Farbe, mit geringen narbigen Einziehungen versehen. Unter der Tube im Lig. latum, vom uterinen Ende der Tube beginnend, eine $4 \mathrm{~cm}$ lange, federkieldicke Auftreibung (thrombosirte Vena spermatica).

Bei Lupenvergrösserung erkennt man auf dem Querschnitte dieser Auftreibung 3 kleinere und ein grösseres Gefäss mit Thromben erfüllt.

Bei stärkerer Vergrösserung sieht man, dass die Thromben 
der kleineren Gefässe aus rothen Blutkörperchen und einem feinen Fibrinnetz bestehen. Die Form der rothen Blutkörperehen ist zum grössten Theil noch orhalten, ein Theil ist zerfallen und in krümliches Pigment umgewandelt, das von grösseren Zellen aufgenommen wird. In der Nähe der Gefässwand zeigen die Thromben mehr oder weniger ausgebildete Organisation.

Das grosse Gefäss, die Vena spermatica, enthält einen alten, fast vollständig organisierten Thrombus, aber mit centralem bröckligen Zerfall. Er ist mit der Gefässwand innig verwachsen und besteht aus einer dichteren centralen und einer lockeren pheripheren Schicht.

Die dichte centrale Schicht zeigt organisirtes Gewebe, welches stark mit Eiterkörperchen infiltrirt ist und am Innenrand zu bröckligem Zerfall neigt. Die der Gefässwand anliegende lockre Schicht enthält junges Bindegewebe mit spindelförmigen Kernen, viele Capillaren mit zartem Endothel, homogene thrombosirte Massen und leukocytäre Infiltration. In der Umgebung der Gefässe bemerkt man eine lebhafte Injektion der Capillaren nebst Vermehrung. Die leukocytäre Infiltration ist durch die Gefässwände hindurch in das lockere Bindegewebe gedrungen und infiltrirt dies theils diffus, theils in Form perivasculärer Herde.

Bei diesem Befunde kann wohl über den ursächlichen Zusammenhang von eitrig zerfallendem Thrombus der V. sperm. dextra und den am 37. Tage des Wochenbettes auftretenden

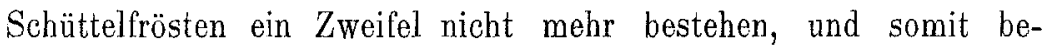
gründet sich die Anzeigestellung und der Zeitpunkt zur operativen Entfernung dieses Thrombus nicht nur durch den pathologisch anatomischen Befund, sondern auch durch den Erfolg.

Nur die eine Frage lässt sich noch stellen; ob es nicht vielleicht vorsichtiger und richtiger gewesen wäre, auch noch die linke Vena spermat. int. zu unterbinden bezw. zu entfernen, da man doch nie wissen kann, ob in einer scheinbar nur mit flüssigem Blut gefüllten. Vene nicht schon feine, wandständige, nur Eitermaterial enthaltende Thromben enthalten sind.

Hierauf kann nur ein grösseres operatives Material endgültige Antwort geben. Dass die Unterbindung beider Venae sperm. int. nicht in jedem Falle unbedingt nothwendig ist, lehrt die vorliegende Krankengeschichte wohl mit voller Sicherheit.

Fasst man zum Schluss die Haupt- und Grundsätze zusammen, 
welche sich aus den 18 operirten Fällen ergeben, so lauten sie folgendermaassen:

1. Gonorrhöische Infektion kurz vor Beginn oder während der Schwangerschaft kann das Wochenbett viel gefährlicher gestalten, als allgemein angenommen und geglaubt wird. Dies beweisen namentlich solche Fälle, bei welchen die Gebärenden innerlich von Niemandem untersucht worden sind (No. 4, 15, 16, 17 der Tabelle).

2. Bei solchen inficirten Frauen kann hohes Fieber mit dem Zeichen beginnender Peritonitis schon am 3. Tage p. p., in manchen Fällen erst am 6. Tage p. p., als sogenanntes Spätfieber auftreten. Gerade letzteres ist bekanntlich für gonorrhoische Infektion sehr charakteristisch, und kann ausserordentlich schwer mit akuter Peritonitis bezw. Thrombophlebitis, die in kurzer Zeit zum Tode führen, einsetzen.

3. Von grosser Gefahr sind wochenlang sich hinschleppende Abortblutungen, namentlich wenn sie mit Fieber verbunden sind. Nach erfolgter Ausstossung des Eies kann hier durch die im Uteruscavum angesammelten Infektionsträger sich sofort akute Peritonitis bezw. Thrombophlebitis anschliessen.

4. Von den verschiedenen Zeichen beginnender Peritonitis bezw. Thrombophlebitis sind die ernstesten der hohe kleine Puls, der Singultus, event. das Erbrechen und die Schüttelfröste. In zweiter Linie kommen dann der spontane Leibschmerz oder der Schmerz bei Betastung, sowie der Meteorismus und bei der Thrombophlebitis die Schmerzen in der Fossa ovalis und die Oedeme der Füsse und Beine.

5. Ist die Diagnose auf beginnende akute Peritonitis gestellt, so darf nicht später als am 3. Tage nach Beginn derselben die Eröffnung der Bauchhöhle zum Ablass des Eiters ausgeführt werden. Auf jeden Fall ist der Douglas'sche Raum nach der Scheide hin von der Linea alba aus zu eröffnen, durchzuspülen und zu drainiern. Zweckmässig ist die Eröffnung und Drainirung der Bauchhöhle auch in den Flanken.

6. Bei der Nachbehandlung ist die allergrösste Aufmerksamkeit darauf zu verwenden, dass von den Oeffnungen der Drainröhren aus nicht secundäre Infektion eintritt.

7. Handelt es sich um Thrombophlebitis purulenta puerperalis, ohne Betheiligung des Peritoneum, so ist nach unseren jetzigen Erfahrungen und nach dem heutigen Stande der Wissenschaft in erster Linie in Betracht zu ziehen, dass der Leib eröffnet 
508 Leopold, Zur operativen Behandlung der puerperalen Peritonitis.

und die betr. thrombosirte, von Eiter erfüllte Vene aufgesucht, unterbunden und entfernt wird.

Die beste Methode ist hier die transperitoneale. Der richtige Zeitpunkt ist gekommen, wenn Schüttelfröste auf die Verschleppung von Thrombenbröckeln hinweisen und seit $1-2$ Tagen aufgetreten sind.

8. Angesichts der Thatsache, dass nach anfänglich gutartigem Verlaufe einer ein- oder doppelseitigen Thrombose der Vena femoralis bez. der iliacae externae sich pyämisches Fieber, welches auf eitrigem Zerfall der Thromben und Verschleppung der Eiterbröckel beruht, sogar noch spät anschliessen kann, so erscheint die möglichst frühzeitige Aufsuchung und Abbindung der thrombo-

\begin{tabular}{|c|c|c|c|c|c|}
\hline 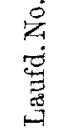 & Name, Alter & $\begin{array}{c}\text { Jahr, Datum, } \\
\text { Geb.-No. }\end{array}$ & ?para & $\begin{array}{l}\text { Frühere Geburten, } \\
\text { event. Krankheiten }\end{array}$ & Jetzige Geburt \\
\hline
\end{tabular}

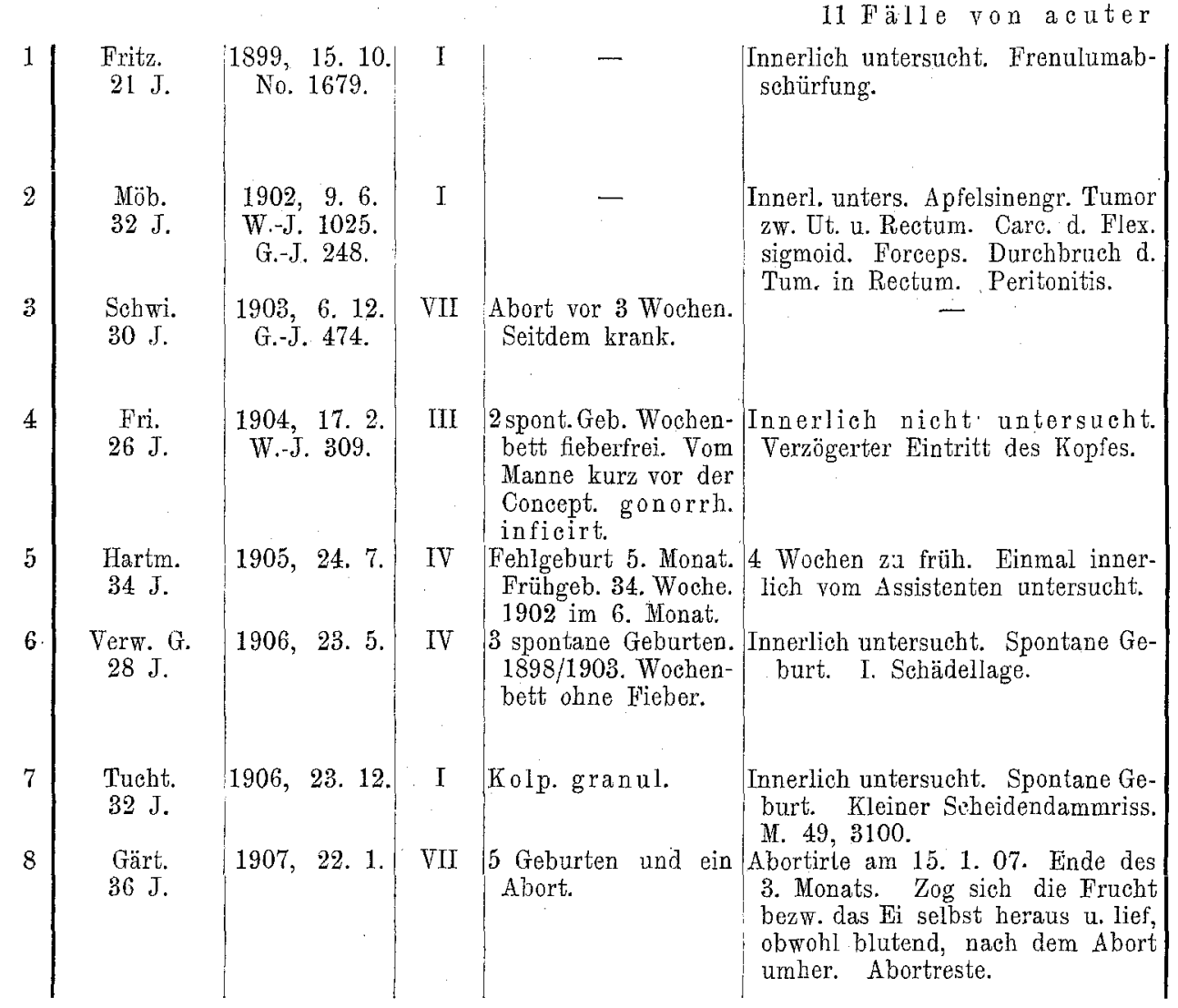


Leopold, Zur operativen Behandlung der puerperalen Peritonitis. 509

sirten Venae iliacae bezw. der Venac spermaticae internae, ja im einzelnen Falle selbst aller 4 Venen, je nach der Schwere des Falles, durchaus begründet.

9. Hierbei halte sich der Operateur immer vor Augen, dass die Gefahr, in welcher die Kranke bei Beginn einer Peritonitis oder bei ciner Thrombophlebitis purulenta sich befindet, immer eine viel ernstere und drohendere ist, als die, welche in dem operativen Eingriff liegt, und dass umgekehrt bei längerem Zaudern und fortwährendem Zuwarten die Laparotomie für den nunmehr sehr gesehwächten Körper zu gefäbrlich, ja ganz aussichtslos ist.

Der Leitstern muss sein: Früh genug; aberniezu spät!

\begin{tabular}{|c|c|c|c|c}
\hline $\begin{array}{c}\text { Inficirt } \\
\text { ubernommen. } \\
\text { Gonorrhoe? }\end{array}$ & $\begin{array}{c}\text { Erkrankung } \\
\text { im Wochenbett }\end{array}$ & Anzeige und Vornahme & Ausgang & Bemerkungen \\
\hline
\end{tabular}

puerperaler Peritonitis.

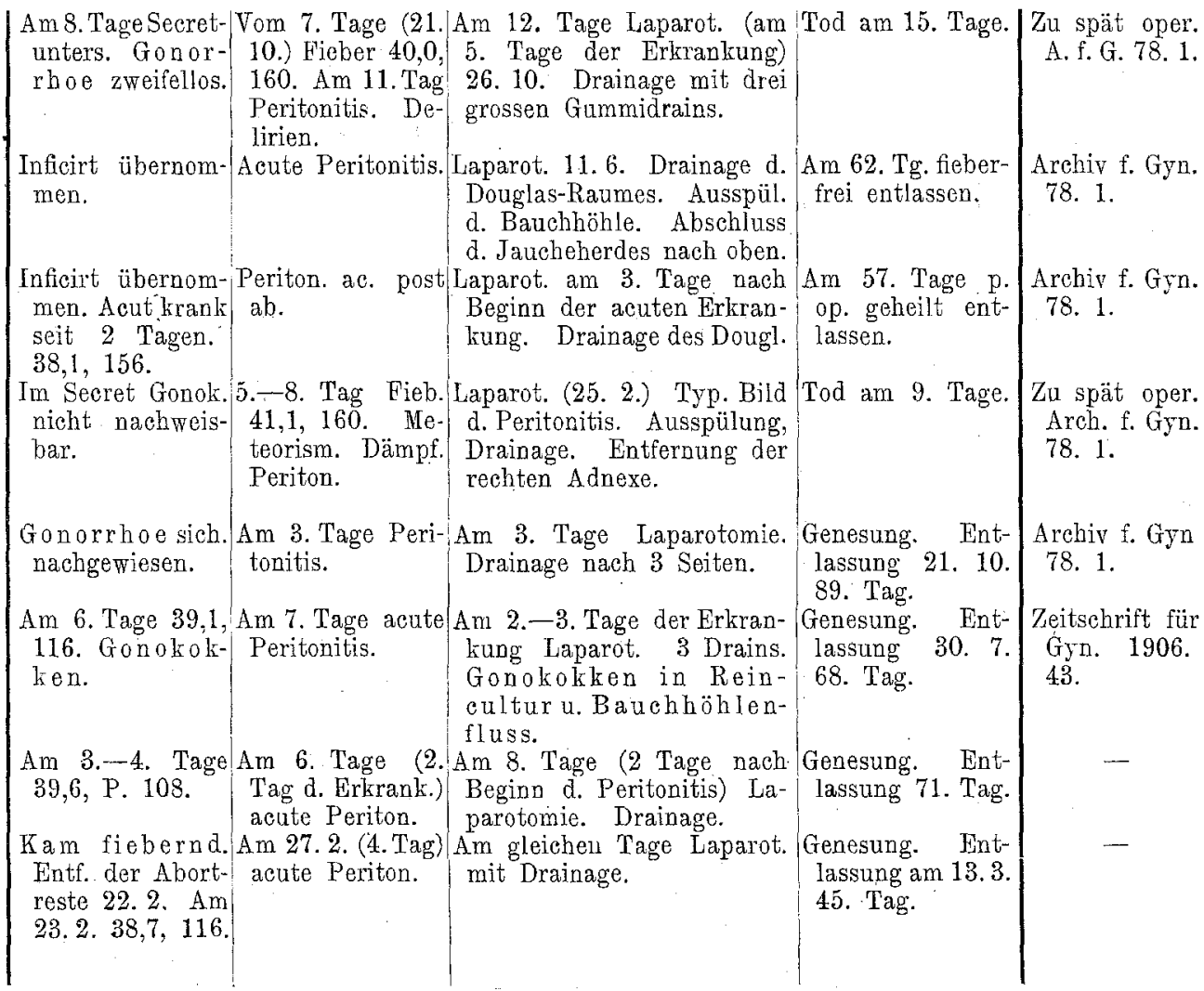


510 Leopold, Zur operativen Behandlung der puerperalen Peritonitis.

\begin{tabular}{|c|c|c|c|c|c|}
\hline 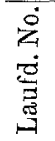 & Name, Alter & $\begin{array}{l}\text { Jahr, Datum, } \\
\text { Geb.-No. }\end{array}$ & ? para & $\begin{array}{l}\text { Frühere Geburten, } \\
\text { event. Krankheiten }\end{array}$ & Jetzige Geburt \\
\hline 9 & $\begin{array}{l}\text { Seif. } \\
26 \mathrm{~J}\end{array}$ & $1907,21.2$. & $\mathrm{I}$ & - & $\begin{array}{l}\text { Innerl. unters. Allg. verengt. platt- } \\
\text { rachit. B. Vera } 7 \% \text {. Blasensprung } \\
\text { ausserhalb. Forceps. Kn. } 52,3500 \text {. }\end{array}$ \\
\hline 10 & $\begin{array}{l}\text { Wie. } \\
20 \mathrm{~J} \text {. }\end{array}$ & 1907, 26. 2. & $I$ & $\begin{array}{l}\text { Puella publica. Von } \\
\text { Mitte Decbr. 06 bis } \\
\text { Ende Januar 07 im } \\
\text { Krankenh. weg. Lues } \\
\text { behand. Letzte Reg. } \\
\text { Anfang Septbr. 06. }\end{array}$ & $\begin{array}{l}\text { Spontane Frühgeburt. Ende } 5 \text { Mo- } \\
\text { nat. Hat am Vorabend noch } \\
\text { wiederholt coirt. }\end{array}$ \\
\hline 11 & $\begin{array}{l}\text { För. } \\
26 \mathrm{~J} \text {. }\end{array}$ & $1907,1.12$. & II & $\begin{array}{l}\text { Vor } 2 \text { Jahren Abort } \\
\text { im 2. Monat. }\end{array}$ & $\begin{array}{l}\text { Seit } 4 \text { Wochen wiederholt } \\
\text { hohes Fieber. Seit } 4 \text { Wochen } \\
\text { fortwährend Blutabgang. }\end{array}$ \\
\hline
\end{tabular}

2 Fällevon puerperaler

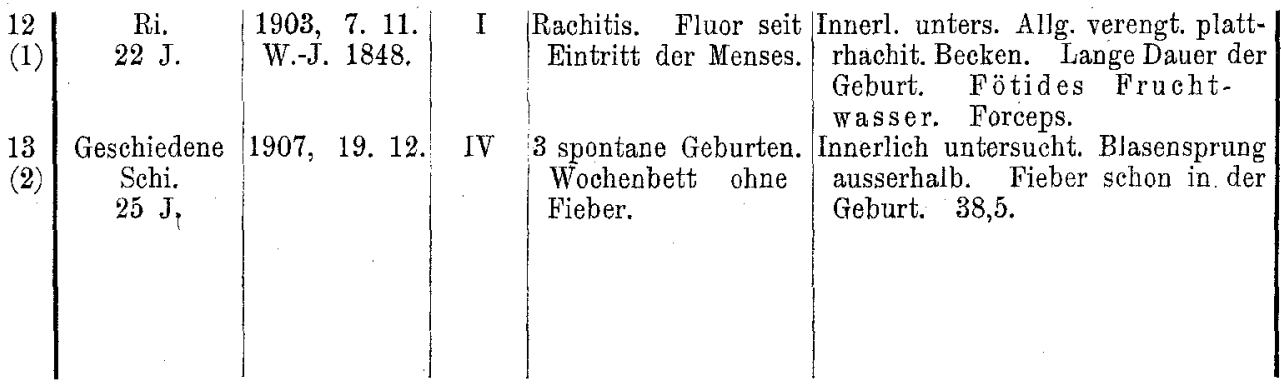

2 Fäle von Peritonitis puerp. circumscripta bezw. universalis

\begin{tabular}{c|c|}
14 & Halb. \\
(1) & $32 \mathrm{~J}$. \\
& \\
15 & $\mathrm{Ri}$. \\
& $20 \mathrm{~J}$.
\end{tabular}

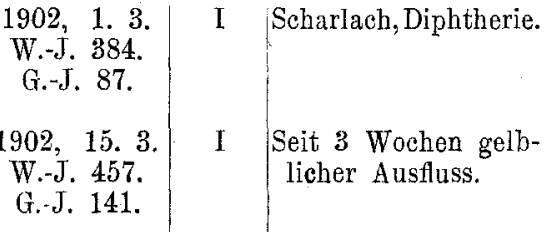
Innerlich untersucht. AlIg. ver
engtes Becken. Frenulumabschür-
fung. Eihautreste.

3 Fälle von Peritonitis puerper. circumseripta

\begin{tabular}{|c|c|c|c|c|}
\hline $\begin{array}{l}\mathrm{He} \text {. } \\
19 \mathrm{~J}\end{array}$ & $\begin{array}{c}1899,21.9 . \\
\text { G.-J. } 1489 . \\
\text { G.-J. } 365 .\end{array}$ & I & Lues heredit. & $\begin{array}{l}\text { Innerlich nicht untersucht. } \\
\text { Frenulumabschürfung. Kind leicht } \\
\text { asphyktisch. }\end{array}$ \\
\hline $\begin{array}{l}\text { We. } \\
18 \mathrm{~J} .\end{array}$ & $\begin{array}{l}1899,25.12 . \\
\text { No. } 2041 .\end{array}$ & 1 & - & $\begin{array}{l}\text { Innerlich nicht untersucht. } \\
\text { Blasensprung ausserbalb. }\end{array}$ \\
\hline $\begin{array}{l}\text { Lehn. } \\
24 \mathrm{~J} \text {. }\end{array}$ & $\begin{array}{c}1903,1.10 . \\
\text { W.-J. } 1645 . \\
\text { G.-J. } 420 .\end{array}$ & $I$ & $\begin{array}{l}\text { Vor 1Jahre Alexander- } \\
\text { Adams. }\end{array}$ & $\begin{array}{l}\text { Innerlich untersucht. Sprengen d. } \\
\text { Blase. Kristeller. }\end{array}$ \\
\hline
\end{tabular}




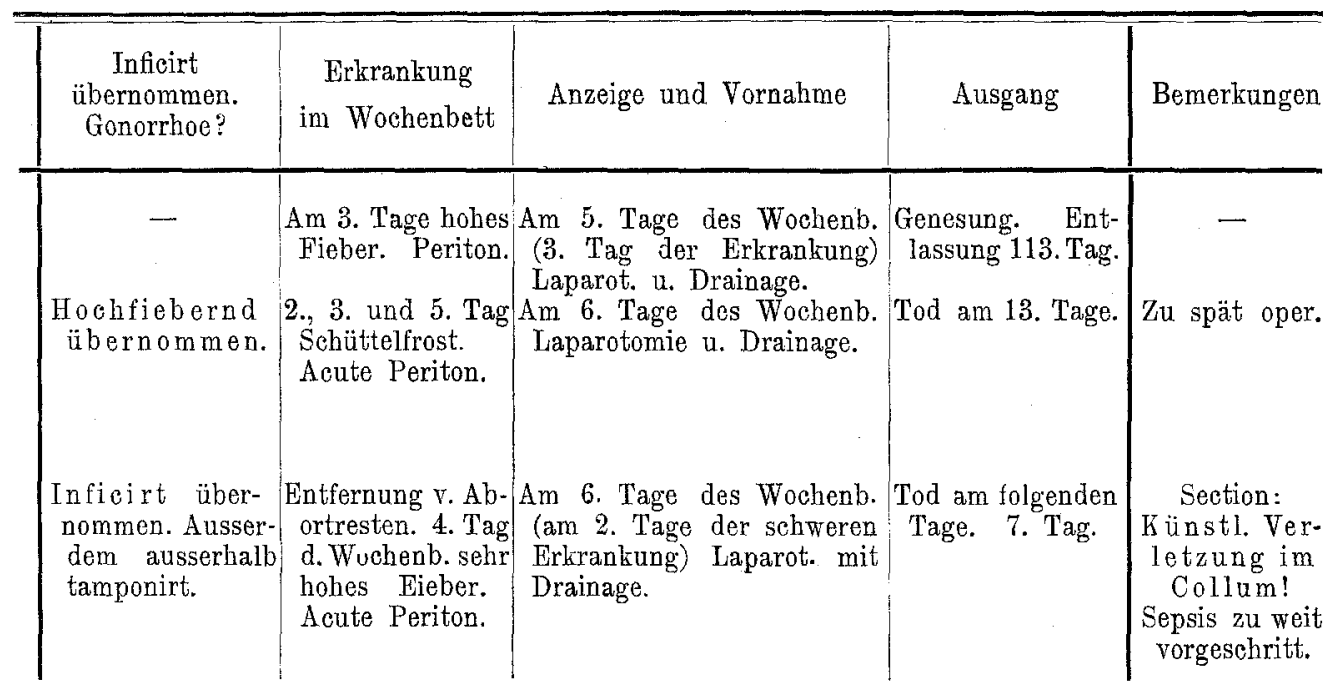

Thrombophlebitis.

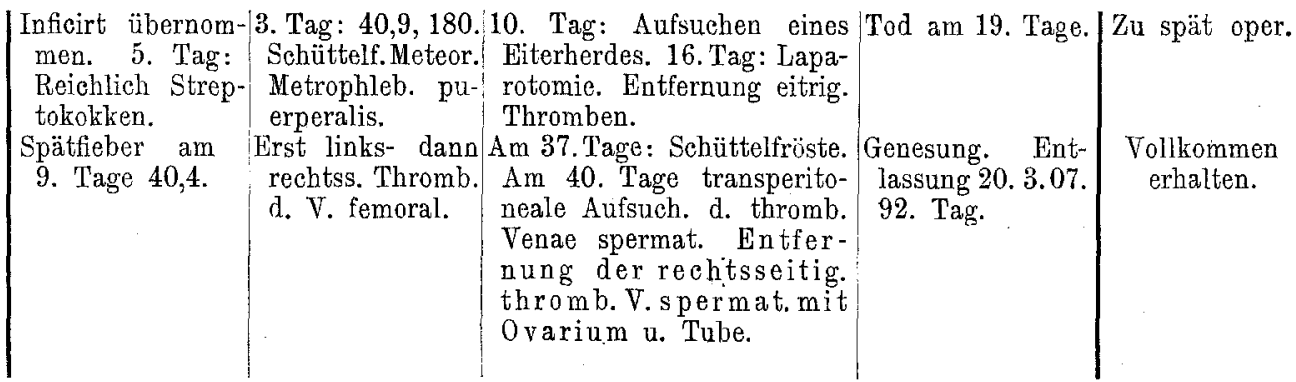

a usgehend von sehwerer Erkrankung der Adnexe einer Seite.

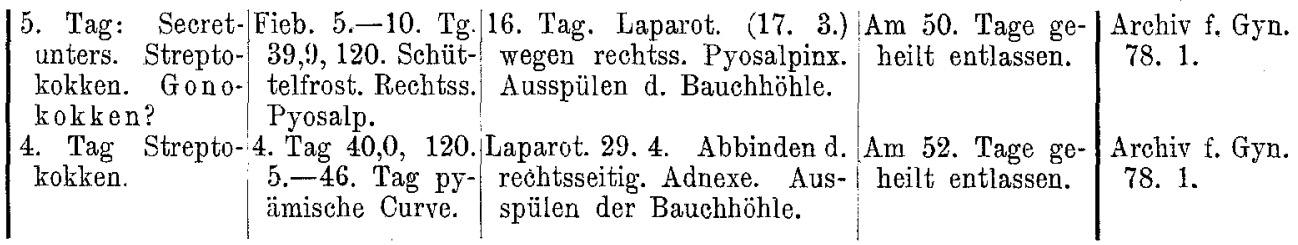

a usgehend von einem Uterusabscess.

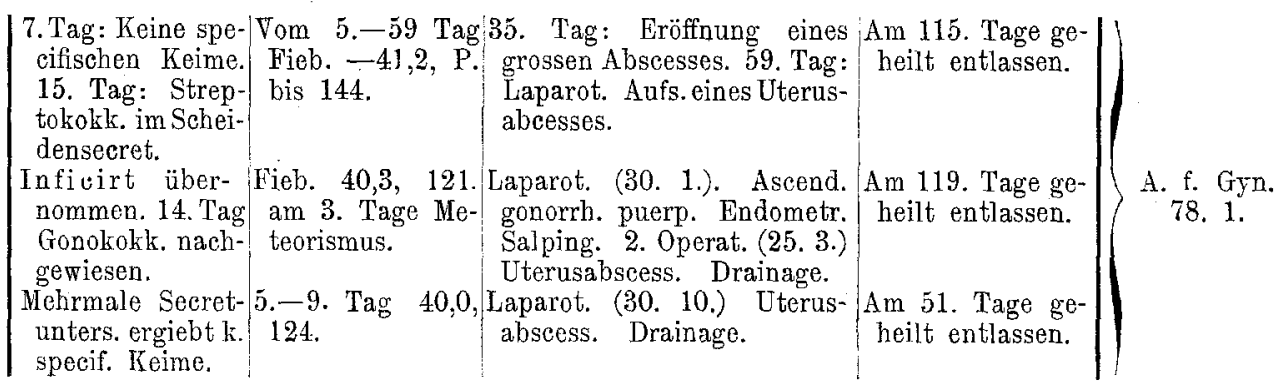

